\title{
Evaluation of Pharmaceutical Quality of Conventional Dosage Forms Containing Paracetamol and Caffeine Available in the Turkish Drug Market
}

\author{
Emrah Akgeyik ${ }^{1}$, Mustafa Sinan Kaynak ${ }^{1}$, Mustafa Çelebier², \\ Sacide Altnö̈z², and Selma Şahin ${ }^{3, *}$ \\ ${ }^{1}$ Inönü University, Faculty of Pharmacy, Department of Pharmaceutical Technology, 44280, Malatya, Turkey \\ ${ }^{2}$ Hacettepe University, Faculty of Pharmacy, Department of Analytical Chemistry, 06100, Ankara, Turkey \\ ${ }^{3}$ Hacettepe University, Faculty of Pharmacy, Department of Pharmaceutical Technology, 06100, Ankara, Turkey
}

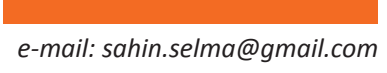

\section{ABSTRACT}

The aim of this study was to evaluate the quality of conventional paracetamol- (PA) and caffeine- (CA) containing combined dosage forms in the Turkish drug market. For this purpose, weight variation, content uniformity, diameter and thickness, hardness, friability, disintegration, and dissolution tests were carried out. Content uniformity and dissolution tests were performed by a validated high-performance liquid chromatography (HPLC) method. Separations were carried on an ACE $5-C_{18}, 5-\mu \mathrm{m} \mathrm{LC} \mathrm{column}(250 \times 4.6 \mathrm{~mm})$ using isocratic elution with a methanol/water (40:60 v/v) mobile phase. The injection volume was $20 \mu \mathrm{L}$, and UV detection was performed at $270 \mathrm{~nm}$. The weight variation results were in accordance with content uniformity results. All dosage forms fulfilled the USP requirement of not less than $75 \%$ of active ingredients of the labeled claim dissolved within $60 \mathrm{~min}$. Also, all tablets met the rapidly dissolving criterion (more than $85 \%$ of the labeled amount of the drug substance dissolved within $30 \mathrm{~min}$ ). The results of this study indicate that PA- and CA-containing conventional dosage forms available in the Turkish drug market pass all the established quality control tests successfully, and they can be used interchangeably.

KEYWORDS: Paracetamol; caffeine; quality control; Turkish drug market; HPLC.

\section{INTRODUCTION}

T he term quality control (QC) refers to the sum of all procedures undertaken to ensure the quality of all factors involved in the production of a particular pharmaceutical (1). It not only protects the manufacturer against compensation claims but also guarantees the patient a safe and effective product; therefore, QC is crucial to the pharmaceutical industry. Numerous tests are performed at every stage of production to ensure that quality is not compromised and that Good Manufacturing Practices are followed. The independence of QC from production is considered fundamental to the satisfactory operation of production (2).

The evaluation and assessment of a tablet's chemical, physical, and bioavailability properties are especially important in tablet design and for monitoring product quality. Various standards should be used to control the pharmaceutical quality of tablet dosage forms. The standard QC tests carried out on tablets include weight variation, content uniformity, diameter and thickness, hardness, friability, disintegration, and dissolution.
In this study, we investigated the pharmaceutical quality of conventional dosage forms containing paracetamol (PA) and caffeine (CA) of different brands marketed in Turkey. The results of the QC tests were compared. A high-performance liquid chromatography (HPLC) method used for the content uniformity and dissolution tests was modified according to the methods reported in the literature (3-7).

\section{MATERIALS AND METHODS \\ Chemicals and Reagents}

PA and CA were purchased from Sigma-Aldrich (St. Louis, Missouri, USA). The methanol used in the content uniformity test and HPLC analysis was HPLC-grade solvent and supplied by Merck (Darmstadt, Germany).

\section{Tablet Samples}

Two different dose combinations of PA and CA tablets are available in the Turkish drug market, namely PA/CA $500 / 30 \mathrm{mg}$ and PA/CA 500/65 mg. Before the QC studies, tablets were labeled randomly as " $\mathrm{A}$," " $\mathrm{B}$," " $\mathrm{C}$," and " $\mathrm{D}$ " for tablets containing $500 \mathrm{mg} P A$ and $30 \mathrm{mg} C A$, and " $\mathrm{E}$ " and " $F$ " for tablets containing $500 \mathrm{mg} \mathrm{PA}$ and $65 \mathrm{mg} C A$. 


\section{Apparatus and Equipment}

A Thermo Finnigan Survey HPLC equipped with a UVdiode array detector and an isocratic/gradient pump was used for the HPLC analysis. Hardness, diameter, and thickness of the tablets were measured using a Pharma Test PTB 311E, 3-in-1 hardness, diameter, and thickness tester (Hainburg, Germany). Friability of the dosage forms was determined via a Pharma Test Variable Speed Friabilitor PTF 10ER (Hainburg, Germany). Dissolution studies were performed with a Pharma Test DT70 dissolution test apparatus (Hainburg, Germany). A Sartorius AX224 analytical balance (Goettingen, Germany) was used to weigh the tablets.

\section{Quality Control Tests}

Tests for weight variation, friability, diameters and thickness, hardness, disintegration time, dissolution, and content uniformity of the active ingredients (PA and CA) were carried out on the tablets as the QC tests.

\section{Weight Variation Measurements}

Weight variation is used to show tablet content uniformity. For the determination of weight variation, 10 tablets from each commercial brand were chosen randomly and then weighed individually using an analytical balance. The mean weight and standard deviation were calculated.

\section{Friability Test}

A friability test is performed to determine the ability of tablets to withstand abrasion during packaging, handling, and shipping processes. To determine the friability of the tablets, 10 tablets from each commercial brand were weighed separately, and each set of tablets was placed into the friabilator. Then, the tablets were rotated at 25 rpm for 4 min (100 revolutions). After 100 revolutions, the tablets were removed and weighed again. The weight was compared with the initial weight. The loss due to abrasion was taken as a measure of tablet friability, and its value was expressed as a percentage. A maximum weight loss of not more than $1 \%$ is generally considered acceptable.

Measurement of Diameter, Thickness, and Width

The diameter, thickness, and width of all commercial brands tested were measured with a Pharma Test PTB $311 E$ tester. Results are expressed as the mean and standard deviation.

\section{Hardness Test}

The hardness of 10 tablets for each brand was measured by using a hardness tester per USP guidelines (8). The tablet hardness tester measures the degree of force in kilopounds $(\mathrm{Kp})$ required to break a tablet across the diameter.

\section{Disintegration Test}

A disintegration test was performed according to the USP guideline (9). The disintegration time of tablets $(n=6)$ was determined at $37 \pm 2{ }^{\circ} \mathrm{C}$ in water using a disintegration tester.

\section{Content Uniformity Test}

For each commercial brand, 10 tablets were weighed to obtain the average weight and then finely grounded. An amount of powder equivalent to one tablet weight was transferred to a $100-\mathrm{mL}$ volumetric flask, and $70 \mathrm{~mL}$ of mobile phase (MeOH/water, 40:60 v/v) was added. The solution was mixed via vortex for $2 \mathrm{~min}$, sonicated for an additional $20 \mathrm{~min}$, then brought to volume with mobile phase to obtain $5000 \mu \mathrm{g} / \mathrm{mL}$ of PA and $650 \mu \mathrm{g} /$ $\mathrm{mL}$ of CA for the commercial tablets containing $500 \mathrm{mg}$ $\mathrm{PA}$ and $65 \mathrm{mg} \mathrm{CA}$, and $5000 \mu \mathrm{g} / \mathrm{mL}$ of PA and $300 \mu \mathrm{g} / \mathrm{mL}$ of CA for tablets containing $500 \mathrm{mg} P A$ and $30 \mathrm{mg}$ CA. An aliquot of these solutions was removed and then spun in a centrifuge at $5000 \mathrm{rpm}$ for $10 \mathrm{~min}$. The solution was filtered using a $0.45-\mu \mathrm{m}$ membrane filter and diluted with mobile phase up to 100 times before injection into the HPLC system.

\section{Dissolution Test}

In vitro dissolution tests were performed according to the USP guidelines (10). Dissolution studies were performed on six tablets containing PA and CA in $900 \mathrm{~mL}$ of water at $37 \pm 0.5^{\circ} \mathrm{C}$ using Apparatus 2 (paddle method, $100 \mathrm{rpm}$ ). One milliliter of sample was withdrawn and replaced with fresh dissolution medium at predetermined time intervals $(0,10,20,30,40,50$, and $60 \mathrm{~min})$. The samples were diluted 10 times with mobile phase and filtered through a $0.45-\mu \mathrm{m}$ membrane filter. The concentrations of PA and CA in the samples were determined by a validated HPLC method.

HPLC Method for Content Uniformity and Dissolution Test Separations of compounds were carried on an ACE $5-C_{18}$, $5-\mu \mathrm{m} \mathrm{LC}$ column $(250 \times 4.6 \mathrm{~mm})$ at ambient temperature $\left(22-28^{\circ} \mathrm{C}\right.$ ) with a flow rate of $1.0 \mathrm{~mL} / \mathrm{min}$. A mixture of methanol/water (40:60 v/v) was used as the mobile phase, and isocratic elution was used. The injection volume was $20 \mu \mathrm{L}$, and UV detection was performed at $270 \mathrm{~nm}$. Peak identity was confirmed by comparing the retention times. Calibration standards were prepared by diluting $1000-\mu \mathrm{g} / \mathrm{mL}$ PA and $1000-\mu \mathrm{g} / \mathrm{mL}$ CA stock solutions in methanol. The calibration standards for PA $(1.0,5.0,10.0$, 25.0, 40.0, and $60.0 \mu \mathrm{g} / \mathrm{mL})$ and CA $(0.2,0.5,1.0,3.0,5.0$, 7.0 , and $10.0 \mu \mathrm{g} / \mathrm{mL}$ ) were injected six times on different days, and calibration curves were constructed. Interday and intraday precision and accuracy of the method were investigated by replicate analyses of PA (10.0, 25.0, and $40.0 \mu \mathrm{g} / \mathrm{mL})$ and $\mathrm{CA}(0.5,5.0$, and $7.0 \mu \mathrm{g} / \mathrm{mL})$ in three different concentration levels for six times in the same day and on different days. 


\section{RESULTS AND DISCUSSION}

PA is a widely used over-the-counter pain reliever and fever reducer. According to the literature $(11,12)$, it is one of the top 10 prescription medicines distributed through community pharmacies in many countries, including Turkey. There are many brands and forms of PA available in the market. Although generally safe for use at recommended doses, even small overdoses can be fatal $(13,14)$. Therefore, it is important to investigate the pharmaceutical quality of PA-containing dosage forms not only for safety but also interchangeability. This situation prompted us to investigate the pharmaceutical quality of conventional dosage forms containing PA and CA available in the Turkish drug market.

The acceptance criteria for the QC tests of a product are generally based on pharmacopeia, in-house (or manufacturer) limits, and specifications. Various standard QC tests such as weight variation, content uniformity, diameter and thickness, hardness, friability, disintegration, and dissolution have been performed on tablets to ensure product quality. HPLC is one of the unique techniques in $\mathrm{QC}$ laboratories due to its simplicity and ease of application in pharmaceutical analysis. Based on the results of initial experiments, it was decided to use a methanol/water (40:60 v/v) mixture as the mobile phase instead of buffer solutions. Initial experiments and partial method validation studies showed that the HPLC method specified in this study could be used for further studies on quality control of PA and CA tablet dosage forms. The regression equations for the calibration curve of PA and CA were $y=80621 x+328.9$ and $y=18456 x-$ 263.5, respectively. In the regression equations, $y$ is the peak area of the active pharmaceutical ingredient and $x$ is the concentration in $\mu \mathrm{g} / \mathrm{mL}$. Figure $1 \mathrm{a}, \mathrm{b}$ represents the chromatograms of PA and CA tablet solutions containing $50.0 \mu \mathrm{g} / \mathrm{mL}$ of $P A$ and $3.0 \mu \mathrm{g} / \mathrm{mL}$ of $C A$ and $50.0 \mu \mathrm{g} / \mathrm{mL}$ of $\mathrm{PA}$ and $6.5 \mu \mathrm{g} / \mathrm{mL}$ of $\mathrm{CA}$, respectively.

The precision and accuracy of the HPLC method were investigated by intraday and interday studies. The percent bias and relative standard deviation of the developed method are less than $2 \%$, indicating that the HPLC method is precise and accurate for the simultaneous determination of PA and CA. Also, the very low standard deviation (SD) values for the content uniformity test results support this statement (Table 2).

To assure the consistency of dosage units, the drug content of each unit in a batch should be in a narrow range near the claimed label strength. This can be demonstrated by two methods, namely, content uniformity and weight variation tests. In the content uniformity test, the individual content of a drug substance in a number of Dissolution
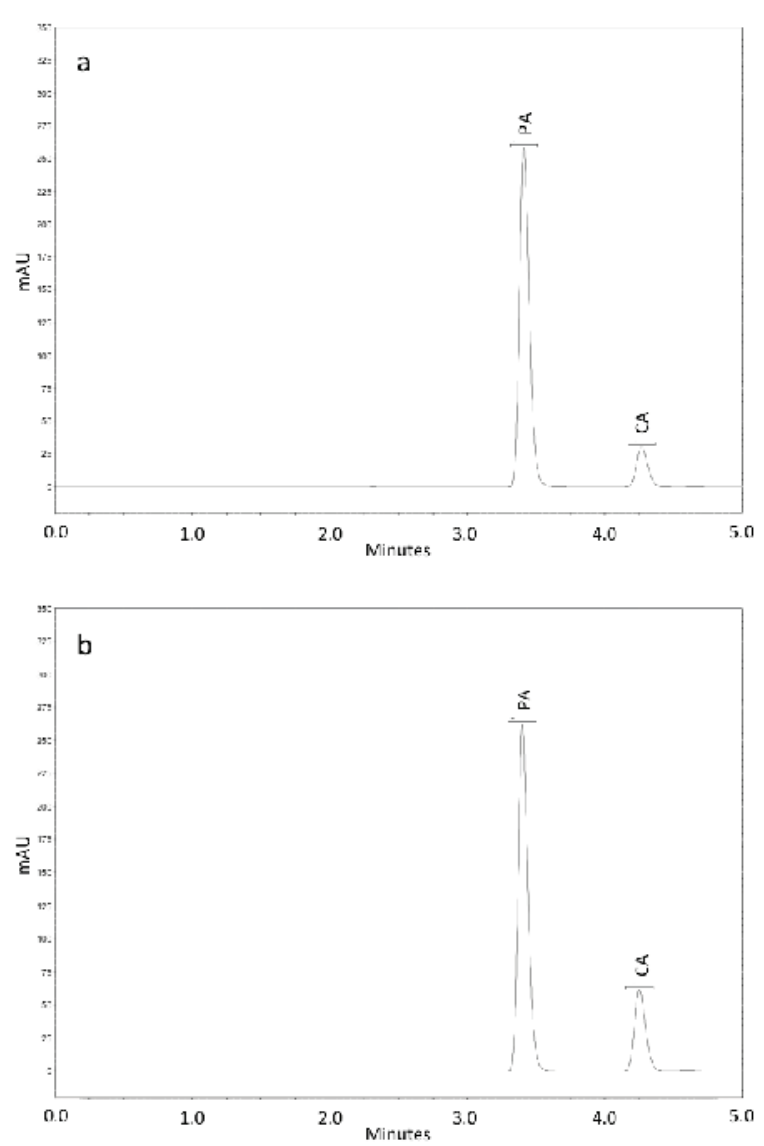

Figure 1. Chromatograms of tablet solutions under optimum experimental conditions: (a) $50.0 \mu \mathrm{g} / \mathrm{mL}$ of $P A$ and $3.0 \mu \mathrm{g} / \mathrm{mL}$ of $C A$ and (b) $50.0 \mu \mathrm{g} / \mathrm{mL}$ of PA and $6.5 \mu \mathrm{g} / \mathrm{mL}$ of $C A$.

individual dosage units is assayed to determine whether the individual content fulfills the set limits. A weight variation test is based on the comparison of individual tablet weights of a sample of tablets with an upper and lower percentage limit of the observed sample average. It is possible that tablets can pass the weight variation requirement but not the content uniformity test. The weight variation and content uniformity results of all dosage forms investigated in this study are given in Tables 1 and 2, respectively.

Because the weight of a compressed tablet is dependent on density, diameter, and thickness, determination of the thickness of the tablets at regular intervals during the production may prevent potential problems related to tablet weight. Hence, content uniformity can be detected at an early stage. Together with friability test, the testing of tablet hardness (i.e., breaking force) plays a pivotal role in both product development and subsequent QC. High hardness values may result in increased disintegration times and decreased dissolution times. On the other hand, hardness values that are too low may cause inappropriately high friability values (15). By examining the correlation between QC parameters (e.g., hardness, 
disintegration, dissolution, friability, and weight variation), the various parameters can be modified to manufacture a dosage form with optimum characteristics. According to the results shown in Tables 1 and 2, the combined dosage forms of PA and CA in the Turkish drug market successfully passed $Q C$ tests.

Table 1. Weight Variation Measurement Results ( $n=10)$
\begin{tabular}{|c|c|c|c|c|}
\hline $\begin{array}{c}\text { Drug } \\
\text { Product } \\
\text { Code }\end{array}$ & $\begin{array}{c}\text { Minimum } \\
\text { Weight (g) }\end{array}$ & $\begin{array}{c}\text { Maximum } \\
\text { Weight (g) }\end{array}$ & $\begin{array}{c}\text { Average } \\
\text { Weight (g) }\end{array}$ & $\begin{array}{c}\text { Standard } \\
\text { Deviation } \\
(\text { SD) }\end{array}$ \\
\hline A & 0.6580 & 0.6818 & 0.6715 & 0.0066 \\
\hline B & 0.6820 & 0.7058 & 0.6972 & 0.0062 \\
\hline C & 0.5934 & 0.6120 & 0.6802 & 0.0257 \\
\hline D & 0.7103 & 0.7334 & 0.7203 & 0.0070 \\
\hline E & 0.6809 & 0.7001 & 0.6925 & 0.0057 \\
\hline F & 0.6390 & 0.6545 & 0.6446 & 0.0048 \\
\hline
\end{tabular}

Drug absorption from a solid dosage form following oral administration depends on three different factors: the release of the drug substance from the drug product, the dissolution (or solubilization) of the drug under physiological conditions, and the permeability of the drug across the gastrointestinal tract. Because the first two steps are critical, in vitro drug dissolution study results are useful to predict the in vivo performance of the drug. The dissolution test measures the time required for a particular drug incorporated in an oral solid dosage form to go into solution under specified conditions. Also, in vitro dissolution studies serve as an indispensable part of drug development. The in vitro drug release information obtained from these studies is routinely used for QC purposes. For immediate-release solid oral dosage forms such as tablets and capsules, the in vitro dissolution test can be employed for an assessment of batch-to-batch QC of a drug product, as a guidance for the development of new formulations, and to maintain the product quality and performance after certain changes (i.e., changes in the formulation, the production process, manufacturing site, and scale-up of the production process). A dissolution test can also be used to support the bioavailability of a new product and to support a request for a waiver of bioequivalence testing (16).

The dissolution profiles of PA and CA in tablets containing $500 \mathrm{mg}$ PA/65 mg CA and $500 \mathrm{mg}$ PA/30 mg CA are given in Figures 2 and 3, respectively. According to the USP (10), not less than $75 \%$ of the active ingredients of the label claims should be dissolved within $60 \mathrm{~min}$. The results of the dissolution studies demonstrate that all tablets examined fulfilled this requirement. According to the Biopharmaceutics Classification System (BCS), CA is a Class 1 compound (high solubility and high permeability) (17). However, there are conflicting reports regarding the BCS classification of PA. It is classified as a Class 3 (high solubility and low permeability) compound by Kalantzi et al. (18). On the other hand, PA is classified as a Class 1 compound according to both the World Health Organization (19) and Benet et al. (20). In the BCS-based biowaiver guidance of the U.S. FDA (21), an immediaterelease drug product is considered "rapidly dissolving" when not less than $85 \%$ of the labeled amount of the drug substance dissolves within $30 \mathrm{~min}$ in three dissolution

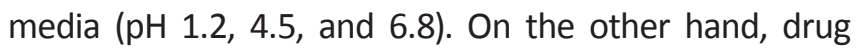
products are considered as "very rapidly" dissolving by the European Medicines Agency (22) when more than $85 \%$ of the labeled amount is dissolved within $15 \mathrm{~min}$

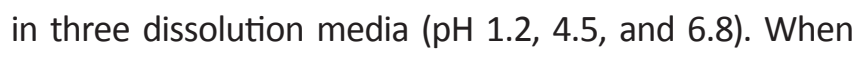
we evaluated our dissolution results, all tablets met the rapidly dissolving criterion for both $\mathrm{PA}$ and $\mathrm{CA}$ under the dissolution conditions used. Some of the tablets (A, B, E, F) even fulfilled the "very rapidly" dissolving criterion (Table 3). All of these results show that the above-mentioned conventional PA and CA combined dosage forms in the Turkish drug market fulfilled both the USP requirement (22-24) and criterion for the rapidly dissolving label.

Table 2. QC Test Results for PA- and CA-Containing Tablets (mean $\pm S D ; n=10$ )

\begin{tabular}{|c|c|c|c|c|c|c|c|c|}
\hline \multirow{2}{*}{$\begin{array}{c}\text { Drug Product } \\
\text { Code }\end{array}$} & Hardness $(\mathrm{Kp})$ & $\begin{array}{c}\text { Diameter } \\
(\mathrm{mm})\end{array}$ & Width $(\mathrm{mm})$ & $\begin{array}{c}\text { Thickness } \\
(\mathbf{c m})\end{array}$ & $\begin{array}{c}\text { Disintegration } \\
(\mathrm{min})\end{array}$ & \multirow{2}{*}{ Friability (\%) } & \multicolumn{2}{|c|}{ Content uniformity } \\
\hline A & $147.47 \pm 7.26$ & $10.58 \pm 0.02$ & Round tablet & $3.12 \pm 0.03$ & $1.21 \pm 0.50$ & 0.091 & $95.73 \pm 1.85$ & $98.41 \pm 3.09$ \\
\hline B & $154.0 \pm 12.82$ & $10.01 \pm 0.01$ & Round tablet & $3.64 \pm 0.02$ & $6.46 \pm 1.00$ & 0.014 & $97.19 \pm 0.97$ & $95.93 \pm 2.48$ \\
\hline C & $126.09 \pm 11.88$ & $10.40 \pm 0.02$ & Round tablet & $2.94 \pm 0.04$ & $10.00 \pm 0.39$ & 0.180 & $97.40 \pm 1.18$ & $96.98 \pm 1.07$ \\
\hline D & $122.99 \pm 15.33$ & $18.60 \pm 0.01$ & $7.60 \pm 0.01$ & $5.40 \pm 0.04$ & $9.89 \pm 0.48$ & 1.079 & $95.61 \pm 3.08$ & $101.66 \pm 2.89$ \\
\hline E & $104.57 \pm 12.89$ & $17.60 \pm 0.01$ & $7.80 \pm 0.01$ & $5.60 \pm 0.05$ & $10.45 \pm 1.22$ & 0.001 & $98.58 \pm 1.84$ & $95.34 \pm 2.20$ \\
\hline F & $183.0 \pm 20.03$ & $9.94 \pm 0.02$ & Round tablet & $3.37 \pm 0.05$ & $8.40 \pm 1.09$ & 0.124 & $97.31 \pm 1.27$ & $92.87 \pm 3.55$ \\
\hline
\end{tabular}

${ }^{a}$ Content uniformity results were obtained by HPLC analysis and represent the percent of label claim. 

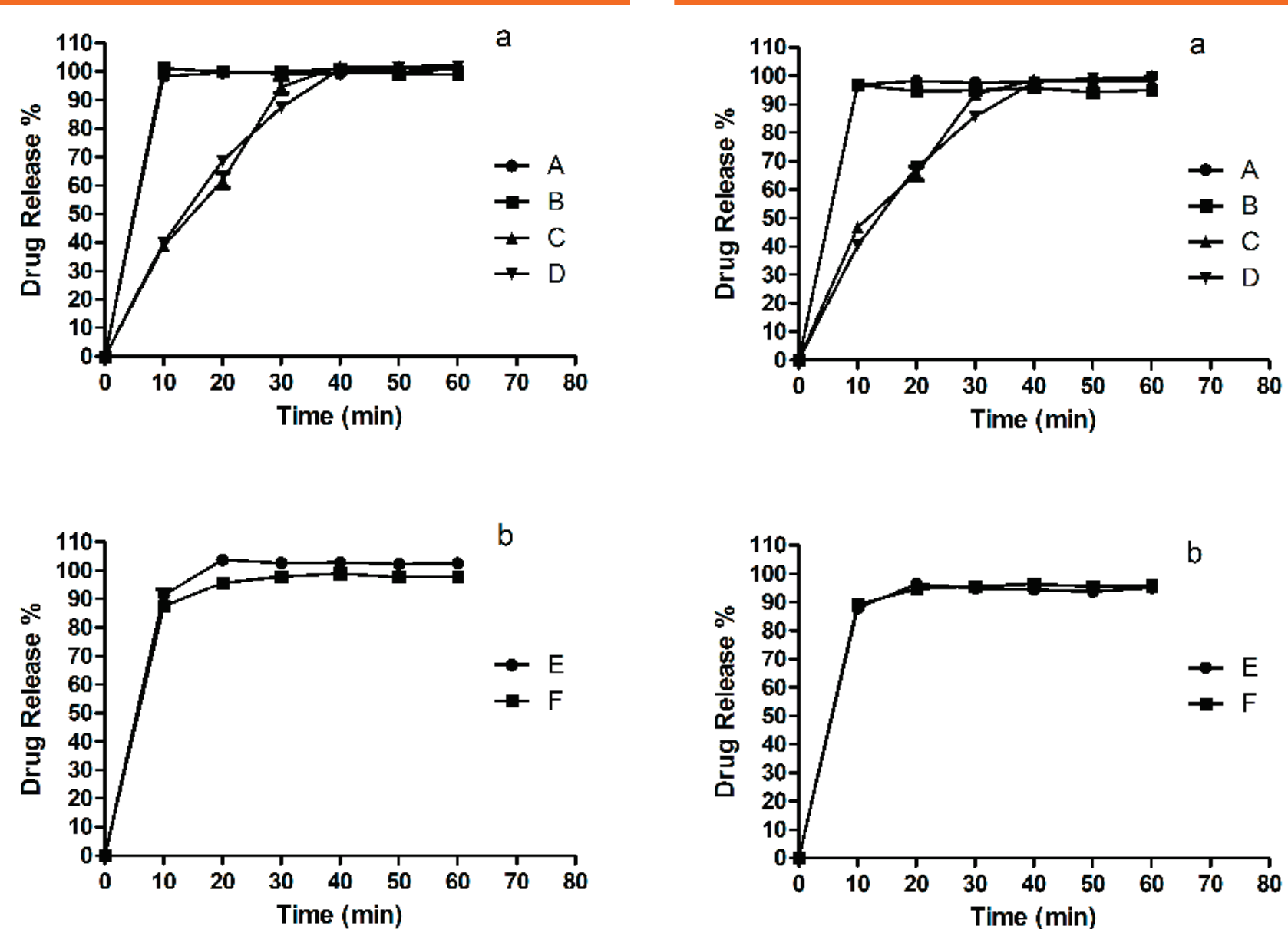

Figure 2. Dissolution profiles of PA from (a) $A, B, C, D(500 \mathrm{mg} P A$, $30 \mathrm{mg} C A)$ and (b) E, F (500 mg PA, $65 \mathrm{mg}$ CA) coded tablets.

Table 3. Dissolution Properties of PA- and CA-Containing Tablets

\begin{tabular}{|c|c|c|c|c|c|c|}
\hline \multirow{2}{*}{$\begin{array}{c}\text { Drug } \\
\text { Product } \\
\text { Code }\end{array}$} & \multicolumn{2}{|c|}{$\begin{array}{c}\text { Very Rapidly } \\
\text { Dissolving }\end{array}$} & \multicolumn{2}{c|}{$\begin{array}{c}\text { Rapidly } \\
\text { Dissolving }\end{array}$} & \multicolumn{2}{c|}{$\begin{array}{c}\text { USP Monograph } \\
\text { Criteria }^{c}\end{array}$} \\
\cline { 2 - 7 } & CA & PA & CA & PA & CA & PA \\
\hline A & + & + & + & + & + & + \\
\hline B & + & + & + & + & + & + \\
\hline C & - & - & + & + & + & + \\
\hline D & - & - & + & + & + & + \\
\hline E & + & + & + & + & + & + \\
\hline F & + & + & + & + & + & + \\
\hline
\end{tabular}

${ }^{a}$ Greater than or equal to $85 \%$ of the labeled amount dissolved in $15 \mathrm{~min}$.

${ }^{b}$ Greater than or equal to $85 \%$ of the labeled amount dissolved in $30 \mathrm{~min}$.

Greater than or equal to $75 \%$ of the labeled amount dissolved in $60 \mathrm{~min}$.

During the manufacture of a solid dosage form such as tablets, a pharmaceutical company usually has to test a large number of QC samples obtained from content uniformity and dissolution studies. In general, HPLC is the method of choice in the pharmaceutical industry for the analysis of a wide variety of samples throughout the production of a dosage form. HPLC is used to check the purity of new drug candidates, monitor changes or the scale-up of synthetic procedures, perform in-process

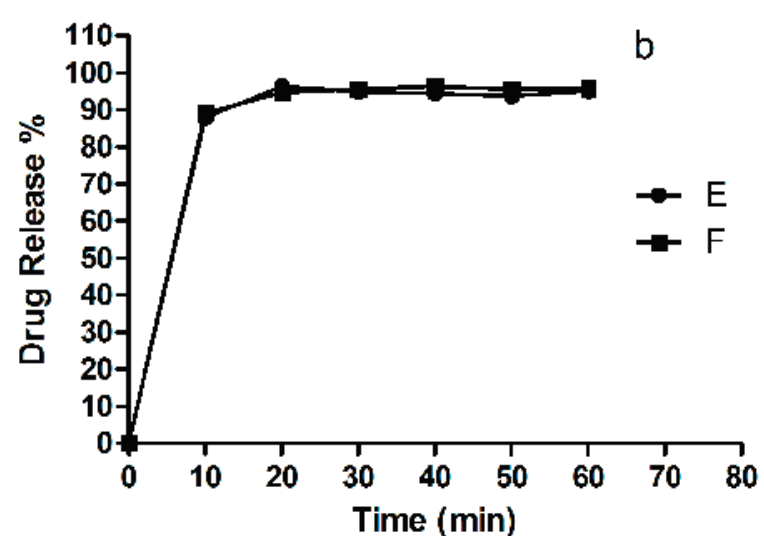

Figure 3. Dissolution profiles of caffeine from (a) $A, B, C, D(500 \mathrm{mg}$ $P A, 30 \mathrm{mg} C A)$ and (b) E, F (500 mg PA, $65 \mathrm{mg} C A)$ coded tablets.

testing for new formulation development, and for $\mathrm{QC} /$ quality assurance of final drug products (25). In this study, we successfully applied the HPLC method for the determination of PA and CA in samples obtained from content uniformity and dissolution studies.

\section{CONCLUSION}

The HPLC method used in this study was successfully applied to content uniformity and dissolution studies. The results of the present study clearly demonstrate that different brands of conventional dosage forms containing PA and CA manufactured in Turkey fulfilled all $\mathrm{QC}$ tests. The weight variation results were in accordance with content uniformity results. Although the dissolution profile shapes were different for dosage forms labeled $A-F$, they all fulfilled the requirement of the USP monograph, and not less than $75 \%$ of the active ingredients as claimed on the label dissolved within $60 \mathrm{~min}$. Also, all tablets met the "rapidly dissolving" criterion (over $85 \%$ of the labeled amount of the drug substance dissolved within $30 \mathrm{~min}$ ). Collectively, all these results indicate that the PA- and CAcontaining conventional dosage forms examined in this study fulfilled the requirements of the established quality control tests, and they can be used interchangeably. 


\section{CONFLICT OF INTEREST}

No conflict of interest has been declared by the authors.

\section{REFERENCES}

1. Quality Control. World Health Organization Web site. http:// www.who.int/medicines/areas/quality_safety/quality_assurance/ control/en/index.html (accessed March 2, 2016).

2. Haleem, R. M.; Salem, M. Y.; Fatahallah, F. A.; Abdelfattah, L. E. Quality in the pharmaceutical industry-A literature review. Saudi Pharm. J. 2015, 23 (5), 463-469. DOI:10.1016/j.jsps.2013.11.004.

3. Franeta, J. T.; Agbaba, D.; Eric, S.; Pavkov, S.; Aleksic, M.; Vladimirov, S. HPLC assay of acetylsalicylic acid, paracetamol, caffeine and phenobarbital in tablets. II Farmaco 2002, 57 (9), 709-713. DOI:10.1016/s0014-827x(02)01265-x.

4. Altun, M. L. HPLC Method for the Analysis of Paracetamol, Caffeine and Dipyrone. Turk. J. Chem. 2002, 26 (4), 521-528.

5. El-Kommos, M. E.; Emara, K. M. Determination of phenyltoloxamine salicylamide, caffeine, paracetamol, codeine and phenacetin by HPLC. Talanta 1989, 36 (6), 678-679. DOI:10.1016/00399140(89)80263-2.

6. Prodan, M.; Gere-Paszti, E.; Farkas, O.; Forgacs, E. Validation and Simultaneous Determination of Paracetamol and Caffeine in Pharmaceutical Formulations by RP-HPLC. Chem. Anal. (Warsaw, Pol.) 2003, 48 (6), 901-907.

7. Xue, H.; Liu, J.; Liu, H.; Wang, G.; Lu, W. Simultaneous determination of paracetamol and caffeine in human plasma by HPLC. Chin. J. Hosp. Pharm. 2005, 25 (8), 708.

8. <1217> Tablet Breaking Force. In The United States Pharmacopeia and National Formulary USP 32-NF 27; The United States Pharmacopeial Convention, Inc.: Rockville, MD, 2009; pp 726-728.

9. <701> Disintegration. In The United States Pharmacopeia and National Formulary USP 32-NF 27; The United States Pharmacopeial Convention, Inc.: Rockville, MD, 2009; pp 262-263.

10. Acetaminophen and Caffeine Tablets Monograph. In The United States Pharmacopeia and National Formulary USP 32-NF 27; United States Pharmacopeial Convention, Inc.: Rockville, MD, 2009; pp 1394-1395.

11. Pharmaceutical Products. Australian Institute of Health and Welfare Web site. http://www.aihw.gov.au/WorkArea/DownloadAsset. aspx?id=6442459447 (accessed March 2, 2016).

12. Usher, C.; Teeling, M.; Bennett, K.; McGowan, B.; Feely, J. Usage of paracetamol-containing combination analgesics remains high in primary care. Br. J. Clin. Pharmacol. 2005, 60 (6), 648-652. DOI: 10.1111/j.1365-2125.2005.02500.x.

13. Dal Pan, G. J. Acetaminophen: Background and Overview. Office of Surveillance and Epidemiology, Center for Drug Evaluation and Research; June 29, 2009; U.S. Food and Drug Administration Web site. http://www.fda.gov/downloads/Advisor.../UCM175767.pdf (accessed March 2, 2016).

14. Roberts, E.; Nunes, V. D.; Buckner, S.; Latchem, S.; Constanti, M.; Miller, P.; Doherty, M.; Zhang, W.; Birrell, F.; Porcheret, M.; Dziedzic,
K.; Bernstein, I.; Wise, E.; Conaghan, P. G. Paracetamol: not as safe as we thought? A systematic literature review of observational studies. Ann. Rheum. Dis. 2016, 75 (3), 552-559. DOI:10.1136/ annrheumdis-2014-206914.

15. Introduction to Tablet Hardness Testing. Copley Scientific Webs site. http://www.copleyscientific.com/home/pharmaceuticaltesting/hardness-testing-breaking-force/introduction-to-tablethardness-testing (accessed March 2, 2016).

16. Sayar, E.; Şahin, S.; Cevheroğlu, Ş.; Hincal, A. A. Comparison of Dissolution Profiles of Two Commercially Available Co-Trimoxazole Tablets. FABAD J. Pharm. Sci. 2008, 33, 87-94.

17. Shugarts, S.; Benet, L. Z. The Role of Transporters in the Pharmacokinetics of Orally Administered Drugs. Pharm. Res. 2009, 26 (9), 2039-2054. DOI:10.1007/s11095-009-9924-0.

18. Kalantzi, L.; Reppas, C.; Dressman, J. B.; Amidon, G. L.; Junginger, H. E.; Midha, K. K.; Shah, V. P.; Stavchansky, S. A.; Barends, D. M. Biowaiver Monographs for Immediate Release Solid Oral Dosage Forms: Acetaminophen (Paracetamol). J. Pharm. Sci. 2006, 95 (1), 4-14. DOI: 10.1002/jps.20477.

19. WHO Expert Committee on Specifications for Pharmaceutical Preparations. Proposal to waive in vivo bioequivalence requirements for WHO Model List of Essential Medicines immediate-release, solid oral dosage forms; WHO Technical Report Series, No. 937, Annex 8; World Health Organization: Geneva, Switzerland, 2006. http://apps.who.int/medicinedocs/en/d/Js19640en/ (accessed March 23, 2016).

20. Benet, L. Z.; Broccatelli, F.; Oprea, T. I. BDDCS Applied to Over 900 Drugs. AAPS J. 2011, 13 (4), 519-547. DOI: 10.1208/s12248-0119290-9.

21. Waiver of In Vivo Bioavailability and Bioequivalence Studies for Immediate-Release Solid Oral Dosage Forms Based on a Biopharmaceutics Classification System; Guidance for Industry; U.S. Department of Health and Human Services, Food and Drug Administration, Center for Drug Evaluation and Research (CDER), U.S. Government Printing Office: Washington, DC, 2000.

22. Guideline on the Investigation of Bioequivalance; CPMP/EWP/ QWP/1401/98; Committee for Medicinal Products for Human Use (CHMP), European Medicines Agency: London, 2010.

23. Dressman, J. B.; Amidon, G. L.; Reppas, C.; Shah, V. P. Dissolution Testing as a Prognostic Tool for Oral Drug Absorption: Immediate Release Dosage Forms. Pharm. Res. 1998, 15 (1), 11-22. DOI: 10.1023/A:1011984216775.

24. Dissolution Testing of Immediate Release Solid Oral Dosage Forms; Guidance for Industry; U.S. Department of Health and Human Services, Food and Drug Administration, Center for Drug Evaluation and Research (CDER), U.S. Government Printing Office: Washington, DC, 1997.

25. Handbook of Pharmaceutical Analysis by HPLC, 1st ed.; Ahuja, S., Dong, M. W., Eds.; Separation Science and Technology, Vol. 6; Elsevier: Amsterdam, 2005. 